\title{
Effect of Fe Addition on Microstructures and Mechanical Properties of Ni- and C-Free Co-Cr-Mo Alloys
}

\author{
Sang-Hak Lee ${ }^{1}$, Naoyuki Nomura ${ }^{2}$ and Akihiko Chiba ${ }^{3}$ \\ ${ }^{1}$ Center for Regional Collaboration in Research and Education, Iwate University, Morioka 020-8551, Japan \\ ${ }^{2}$ Department of Welfare Engineering, Faculty of Engineering, Iwate University, Morioka 020-8551, Japan \\ ${ }^{3}$ Institute for Material Research, Tohoku University, Sendai 980-8577, Japan
}

\begin{abstract}
A series of Co-Cr-Mo alloys with Fe contents ranging from 5 to 20 mass $\%$ were prepared in order to study the effect of Fe addition on the microstructures and mechanical properties (tensile strength, yield strength, elongation, and Rockwell C scale hardness) of $\mathrm{Ni}$ - and $\mathrm{C}$-free $\mathrm{Co}-\mathrm{Cr}$ Mo alloys. Fe was added with the composition of Co-29Cr-6Mo- $x \mathrm{Fe}$ (where $x=0,5,10$, and 20). Alloys were heat-treated at $1230^{\circ} \mathrm{C}$ for $3 \mathrm{~h}$ and $1250^{\circ} \mathrm{C}$ for $5 \mathrm{~h}$. These heat treatment conditions were decided as considering pre-heat treatment followed by hot-forging process. An optical microscope and an XRD were used to determine the microstructure and identify the crystal structure. The volume ratio of $\gamma$ phase to $\varepsilon$ phase increases not only with heat treatment temperature and time but also with Fe content. The tensile strength, yield strength, and elongation are significantly improved by Fe addition. However, the tendency toward $\sigma$ phase formation becomes higher as the Fe content increases, causing a deterioration of mechanical properties. From the viewpoint of mechanical properties, the amount of Fe addition should be less than 10 mass $\%$ in pre-heated condition of Co-29Cr-6Mo alloys. [doi:10.2320/matertrans.MRA2007004]
\end{abstract}

(Received January 9, 2007; Accepted May 15, 2007; Published July 4, 2007)

Keywords: cobalt chromium molybdenum alloy, biomaterial, nickel carbon free, iron

\section{Introduction}

Co-Cr-Mo alloys are used for total hip and knee implant prostheses. It is well known that $\mathrm{Co}-\mathrm{Cr}-\mathrm{Mo}$ alloys possess excellent wear resistance, corrosion resistance, and biocompatibility. ${ }^{1-3)}$ When Co-Cr-Mo alloys are solidified from the liquid phase, the cooling rate of the alloy ingot is slower in the central region than on the surface, leading to a large dendritic structure having a core matrix and large precipitates. Since these act as sites for crack initiation, an as-cast Co-Cr-Mo alloy shows limited ductility and fatigue strength. ${ }^{4,5)}$ Thus orthopedic devices made of cast $\mathrm{Co}-\mathrm{Cr}$ Mo alloy lack in reliability due to an immature fracture during implantation. Therefore, hot-forging is preferred in order to ensure an increase in strength. Forged alloys have been known to be stronger than as-cast or annealed materials. The stable phase at room temperature in Co-based alloy is hcp $\varepsilon$ phase. However, the $\gamma \rightarrow \varepsilon$ transformation is so sluggish that the final structure is usually a mixture of metastable $\gamma$ and $\varepsilon$ phases. ${ }^{6)}$ Besides, $\sigma$ phase formed at grain boundaries, resulting in reduction of hot workability. For the successful hot-forging process, $\sigma$ phase should be removed by the way of pre-heat treatment. In order to increase the hot workability, $\mathrm{Ni}$ is usually added to Co-Cr-Mo alloys. This is due to the fact that $\mathrm{Ni}$ increases the stacking fault energy (SFE) of a Co-Cr-Mo alloy and thereby stabilizes the fcc phase $^{7)}$ that normally exhibits a good plastic deformation behavior owing to its possession of over 5 independent slip system leading to the improved ductility and hot workability. However, Ni causes allergic contact dermatitis. Therefore, people who are highly allergic to nickel should avoid implanting Ni-contained surgical devices. Hence, it is needed to find other elements which substitute for $\mathrm{Ni}$ in the $\mathrm{Co}-\mathrm{Cr}$ Mo alloy for biomedical applications. Among the interstitial solid-solution elements, $\mathrm{C}$ addition precipitates $\mathrm{M}_{23} \mathrm{C}_{6}$ carbides, ${ }^{8)}$ which are quite effective in increasing hardness of as-cast Co-Cr-Mo alloy. On the other hand, coarse carbides in grain boundaries also act as origin for fatigue crack, and high level of $\mathrm{C}$ content will restrict hot forging processes.9) Therefore, it is important to study the microstructure and mechanical properties of $\mathrm{Ni}$ - and $\mathrm{C}$-free $\mathrm{Co}-\mathrm{Cr}$ Mo alloys for development of new biomaterials, and to find the substitute elements for Ni to increase the hot workability. In Co-based alloys, $\mathrm{Fe}, \mathrm{Mn}$, and $\mathrm{Zr}$ stabilize the fcc phase ${ }^{10,11)}$ and raise the SFE in the same way as Ni does. In the previous studies, we have investigated the microstructures and mechanical properties of $\mathrm{Zr}$ added $\mathrm{Ni}$ - and $\mathrm{C}$-free $\mathrm{Co}-\mathrm{Cr}$ Mo alloys, as well as $\mathrm{Ni}$ - and $\mathrm{C}$-free $\mathrm{Co}-\mathrm{Cr}-\mathrm{Mo}$ alloys, which was subjected to pre-heat treatment prior to hot forging process. $^{12,13)}$

In this study, we pay attention to the effect of $\mathrm{Fe}$ on the microstructure and the mechanical properties of a Co-Cr-Mo alloy. In order to determine the optimum hot-forging condition and Fe content, the pre-heat treatment conditions were investigated using as-cast and heat-treated alloys with a varying amount of $\mathrm{Fe}$ addition.

\section{Experimental Procedure}

The alloys used for the present study were melted using a vacuum induction furnace, and solidified with a metallic mold. The analyzed chemical compositions of alloys are given in Table 1 . Alloys referred to as $0 \mathrm{Fe}, 5 \mathrm{Fe}, 10 \mathrm{Fe}$, and $20 \mathrm{Fe}$ in this study, were designed by adding Fe content to a Co-29Cr-6Mo alloy with a composition of Co-29Cr-6Mo$x \mathrm{Fe}$ (where $x=0,5,10$, and 20) (all in mass \%). Exper-

Table 1 Chemical compositions of the experimental alloys (mass\%).

\begin{tabular}{ccccccccc}
\hline Alloys & $\mathrm{Cr}$ & $\mathrm{Mo}$ & $\mathrm{Fe}$ & $\mathrm{Ni}$ & $\mathrm{C}$ & $\mathrm{Si}$ & $\mathrm{Mn}$ & $\mathrm{Co}$ \\
\hline $20 \mathrm{Fe}$ & 28.77 & 5.48 & 19.52 & 0.01 & $<0.005$ & 0.07 & $<0.01$ & Bal. \\
$10 \mathrm{Fe}$ & 28.83 & 5.72 & 9.92 & 0.03 & $<0.005$ & 0.07 & $<0.01$ & Bal. \\
$5 \mathrm{Fe}$ & 28.23 & 6.05 & 5.07 & 0.03 & $<0.005$ & 0.07 & $<0.01$ & Bal. \\
$0 \mathrm{Fe}$ & 28.80 & 5.61 & 0.05 & 0.17 & $<0.005$ & 0.07 & $<0.01$ & Bal. \\
\hline
\end{tabular}




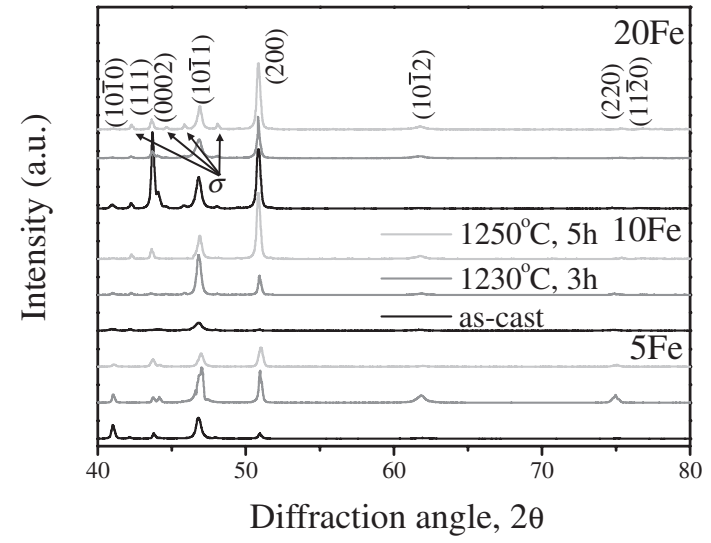

Fig. 1 Effect of Fe addition and heat treatment condition on the XRD pattern of Co-29Cr-6Mo alloys.

imental alloys were heat-treated at $1230^{\circ} \mathrm{C}$ for $3 \mathrm{~h}$ and at $1250^{\circ} \mathrm{C}$ for $5 \mathrm{~h}$ in a tube chamber furnace using a halogen lamp heating system under an atmosphere of high purity Ar gas. The temperature control during the heat treatment was done with precision of $\pm 5^{\circ} \mathrm{C}$. The heat-treated alloys were water-quenched immediately after the heat treatment. The microstructures of as-cast and heat-treated specimens were characterized by using an optical microscope (OM). The samples for OM and X-ray diffraction (XRD) were prepared from specimen cross-sections. A surface of experimental alloys was mechanically ground with emery papers to \#1000, polished with $0.05 \mu \mathrm{m} \mathrm{Al}_{2} \mathrm{O}_{3}$ and then electro-polished at $5 \mathrm{~V}$ for 15 seconds in a 9:1 solution of $\mathrm{CH}_{3} \mathrm{OH}: \mathrm{H}_{2} \mathrm{SO}_{4}$. The dimension of samples for XRD were $15 \mathrm{~mm} \times 15 \mathrm{~mm} \times$ $2 \mathrm{~mm}$. In order to examine crystal structures over the wider area, samples were attached to a rotating sample holder. XRD patterns were measured between $40^{\circ} \leq 2 \theta \leq 80^{\circ}$ using $\mathrm{Cu} \mathrm{K} \alpha$ radiation. The XRD source was generated at $40 \mathrm{kV}$ and $40 \mathrm{~mA}$. The relative intensities of XRD peaks are different from those of theoretical values. We tentatively adopted the integrated intensities of the $(200)_{f c c}$ and $(10 \overline{1} 1)_{h c p}$ $\mathrm{X}$-ray diffraction peaks for estimating the volume ratio of fcc $\gamma$ phase to that of hcp $\varepsilon$ phase. Tensile tests were performed at an initial strain rate of $5.2 \times 10^{-4} \mathrm{~s}^{-1}$ using an Instron type testing machine. The gauge size of the tensile specimens was $16 \mathrm{~mm}$ in length, $3 \mathrm{~mm}$ in width and $1.3 \mathrm{~mm}$ in thickness. A Rockwell C scale hardness measurement was made on polished surfaces of as-cast and heat-treated specimens.

\section{Results and Discussion}

\subsection{X-ray Diffraction Pattern Analysis}

XRD patterns of experimental alloys are shown in Fig. 1. As can be seen in the XRD pattern, the relative intensity of the diffraction peak from $(200)_{f c c}$ to that from $(10 \overline{1} 1)_{h c p}$ significantly increases with increasing $\mathrm{Fe}$ content and heat treatment temperature, indicating that $\mathrm{Fe}$ addition stabilizes the $\gamma$ phase. Diffraction peaks from the $\sigma$ phase were also detected in all as-cast $\mathrm{Fe}$ added alloys, though they completely disappeared after the heat treatment in $5 \mathrm{Fe}$ alloy and almost disappeared after the heat treatment in $10 \mathrm{Fe}$ alloy. However, peaks from the $\sigma$ phase in $20 \mathrm{Fe}$ alloys were still

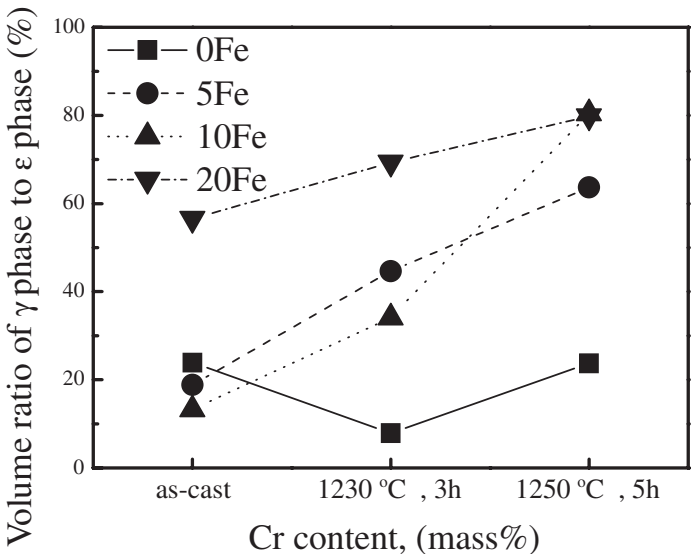

Fig. 2 Effect of Fe addition and heat treatment condition on the volume ratio of $\gamma$ phase to $\varepsilon$ phase of Co-29Cr-6Mo alloys.

clearly detected even after the heat treatment at $1250^{\circ} \mathrm{C}$ for $5 \mathrm{~h}$. We chose two different heat treatment temperature and time in this study; $1230^{\circ} \mathrm{C}$ at $3 \mathrm{~h}$ and $1250^{\circ} \mathrm{C}$ at $5 \mathrm{~h}$. The former condition is commercially adopted to break dendritic structure, remove any harmful precipitates and obtain an fcc structure before hot-forging process. The latter condition was chosen to make sure the aforementioned structure changes. The calculated volume ratio of the $\gamma$ phase to $\varepsilon$ phase in experimental alloys is shown in Fig. 2. The volume ratio of the $\gamma$ phase to that of $\varepsilon$ phase in Fe added alloys significantly increases with increasing heat treatment temperature and time. Most importantly, increasing the Fe content makes the $\gamma$ phase more stable. However, in the case of $0 \mathrm{Fe}$, the volume fraction of the $\gamma$ phase does not increase with heat treatment temperature and time. We reported previously that higher heat treatment temperature (above $1230^{\circ} \mathrm{C}$ ) and longer heat treatment time (over $6 \mathrm{~h}$ ) can suppress the athermal $\gamma \rightarrow \varepsilon$ martensitic transformation. On the other hand, lower heat treatment temperature (below $1200^{\circ} \mathrm{C}$ ) and shorter heat treatment time (under $2 \mathrm{~h}$ ) make the $\gamma$ phase unstable. ${ }^{11)}$ The unstable $\gamma$ phase of $\mathrm{Ni}$ - and $\mathrm{C}$-free $\mathrm{Co}-\mathrm{Cr}$-Mo alloys has a significant tendency to martensitically transform to $\varepsilon$ phase during water quenching process. However, Fe can suppress the $\gamma \rightarrow \varepsilon$ martensitic transformation, so that the $\gamma$ phase remains stable after a relatively shorter heat treatment time and a lower heat treatment temperature.

\subsection{Microstructures}

Figures 3 to 5 show the microstructures obtained with varying Fe contents and heat treatment conditions. Figure 3 shows the microstructures of as-cast alloys. The $0 \mathrm{Fe}$ alloy shows a cored dendritic structure with $\sigma$ (topologically closepacked) phase along the interdendritic region (Fig. 3(a)). The microstructure of the as-cast $5 \mathrm{Fe}$ alloy (Fig. 3(b)) is similar to that of the 0Fe alloy. As shown in Fig. 3(c) and (d), the amount of $\sigma$ phase (indicated by arrow in Fig. 3(c)), formed in the interdendritic region during solidification, considerably increases with $\mathrm{Fe}$ content. In addition, the dendritic structure changes its morphology from a directional dendritic structure to a fine equiaxed dendritic structure as the $\mathrm{Fe}$ content increases. Grain growth, concomitant with intergranular striations corresponding to $\varepsilon$ martensite, is recognized in all 

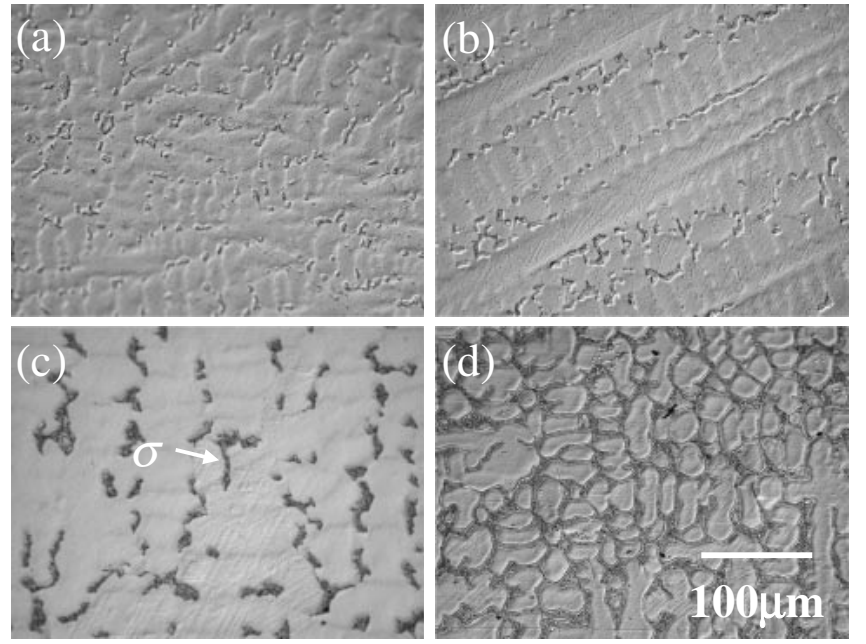

Fig. 3 Effect of Fe addition on the microstructure of as-cast Co-29Cr-6Mo alloys. (a) $0 \mathrm{Fe}$ alloy (b) $5 \mathrm{Fe}$ alloy (c) $10 \mathrm{Fe}$ alloy (d) $20 \mathrm{Fe}$ alloy.
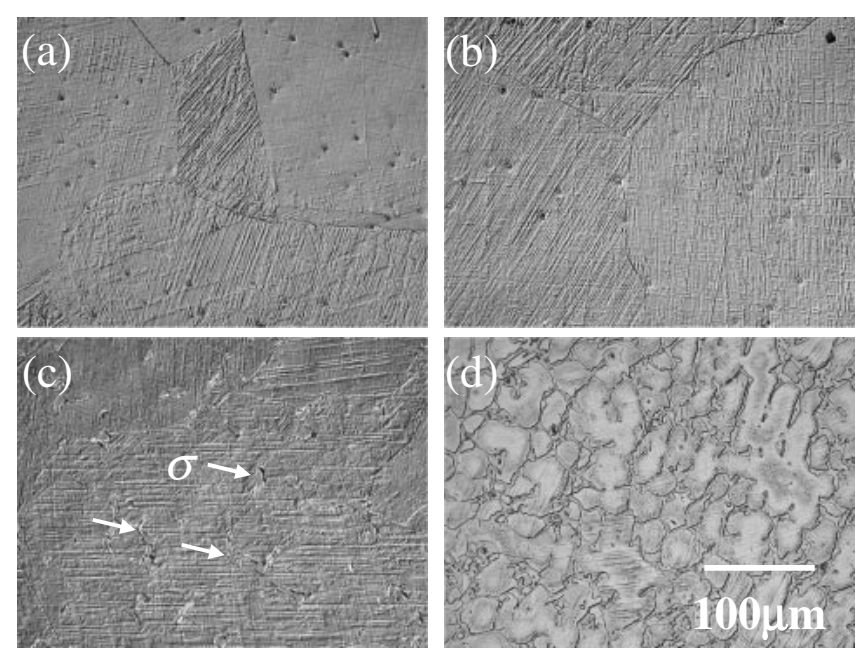

Fig. 4 Effect of Fe addition and heat treatment on the microstructure of Co-29Cr-6Mo alloys heat treated at $1230^{\circ} \mathrm{C}$ for $3 \mathrm{~h}$. (a) $0 \mathrm{Fe}$ alloy (b) $5 \mathrm{Fe}$ alloy (c) $10 \mathrm{Fe}$ alloy (d) $20 \mathrm{Fe}$ alloy.

the alloys after heat treatment except for $20 \mathrm{Fe}$ alloys. The $\varepsilon$ martensite is formed during water quenching by the mechanism of athermal $\gamma \rightarrow \varepsilon$ martensitic transformation, observed as a striation in a grain interior. The $\sigma$ phase observed in $0 \mathrm{Fe}$ and $5 \mathrm{Fe}$ alloys disappears after heat treatment. However, a small amount of the $\sigma$ phase remains at grain boundaries in the $10 \mathrm{Fe}$ alloy heat-treated at $1230^{\circ} \mathrm{C}$ for $3 \mathrm{~h}$ (indicated by arrows in Fig. 4(c)). The $\sigma$ phase of the $10 \mathrm{Fe}$ alloy did not completely dissolve in the matrix even after prolonged heat treatment $(5 \mathrm{~h})$ at higher temperatures such as $1250^{\circ} \mathrm{C}$ in this study (indicated by arrows in Fig. 5(c)). The microstructure of $20 \mathrm{Fe}$ almost does not change its morphology with heat treatment. Although the heat treatment condition is enough for the dissolution of $\sigma$ phase to a matrix in a Co-29Cr-6Mo alloy, ${ }^{12)}$ the $\sigma$ phase still remains in $20 \mathrm{Fe}$ alloys.

To investigate the relationship between the forming tendency of $\sigma$ phase and Fe content, we adopted the PHACOMP method. PHACOMP is a useful technique which
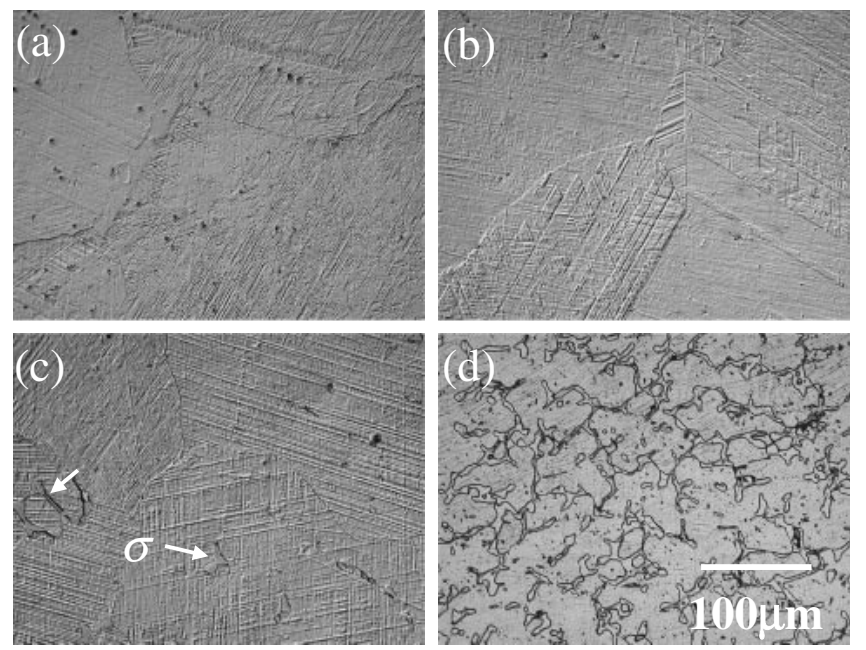

Fig. 5 Effect of $\mathrm{Fe}$ addition and heat treatment on the microstructure of Co-29Cr-6Mo alloys heat treated at $1250^{\circ} \mathrm{C}$ for $5 \mathrm{~h}$. (a) $0 \mathrm{Fe}$ alloy (b) $5 \mathrm{Fe}$ alloy (c) $10 \mathrm{Fe}$ alloy (d) $20 \mathrm{Fe}$ alloy.

Table 2 Calculated $\bar{N}_{v}$ values of the experimental alloys.

\begin{tabular}{ccccc}
\hline Alloys & $0 \mathrm{Fe}$ & $5 \mathrm{Fe}$ & $10 \mathrm{Fe}$ & $20 \mathrm{Fe}$ \\
\hline $\bar{N}_{v}$ & 2.76 & 2.80 & 2.85 & 2.93 \\
\hline
\end{tabular}

predicts the tendency for an austenitic alloy to precipitate TCP phases including $\sigma, \mu, \mathrm{R}, \chi$, and Laves phases, which have a deleterious effect on the ductility. ${ }^{14)}$ According to PHACOMP, the average electron-hole number, $\bar{N}_{v}$ is expressed as:

$$
\bar{N}_{v}=\sum_{i=1}^{n} m_{i}\left(N_{v}\right)_{i}
$$

where $\bar{N}_{v}$ is the average electron-hole number for the alloy, $m_{i}$ is the atomic fraction of the corresponding element, $N_{v}$ is the electron-hole number of the corresponding element and $n$ is the number of elements in the solid-solution alloy matrix. Woodyatt et al. ${ }^{15)}$ estimate the $\sigma$-forming tendency of austenitic alloys as described below:

$$
\begin{aligned}
\bar{N}_{v}= & 0.66[\mathrm{Ni}]+1.71[\mathrm{Co}]+2.66[\mathrm{Fe}] \\
& +4.66[\mathrm{Cr}+\mathrm{Mo}+\mathrm{W}]+5.66[\mathrm{~V}] \\
& +6.66[\mathrm{Zr}]+10.66[\mathrm{Nb}] \quad(\text { all in mol\%) }
\end{aligned}
$$

The characteristic $\bar{N}_{v}$ value indicating the tendency of the $\sigma$ formation is determined by empirical method for each alloy system. According to eq. (2), since the $N_{v}$ value of Fe is higher than that of $\mathrm{Co}$, the $\sigma$ phase formation becomes easy with increasing the Fe content in the replacement of Co. The $\bar{N}_{v}$ values of the present alloys are listed in Table 2. LQ Shi $e t$ al. recommend a $\bar{N}_{v}$ value of 2.70 for Co-based alloys, above which $\sigma$ phases are formed. ${ }^{7)}$ In the present work, as stated above, the $\sigma$ phase completely dissolved in a matrix after heat treatment in the $5 \mathrm{Fe}$ alloy, notwithstanding that the $\bar{N}_{v}$ value of the 5Fe alloy is 2.80 . On the other hand, small amount of the $\sigma$ phase still remained in the $10 \mathrm{Fe}$ alloy with the $\bar{N}_{v}$ value of 2.85 after heat treatment at $1250^{\circ} \mathrm{C}$ for $5 \mathrm{~h}$. Aforementioned $\bar{N}_{v}$ value of 2.70 indicates the start line of $\sigma$ phase formation in equilibrium phase diagram. However, the $\sigma$ 


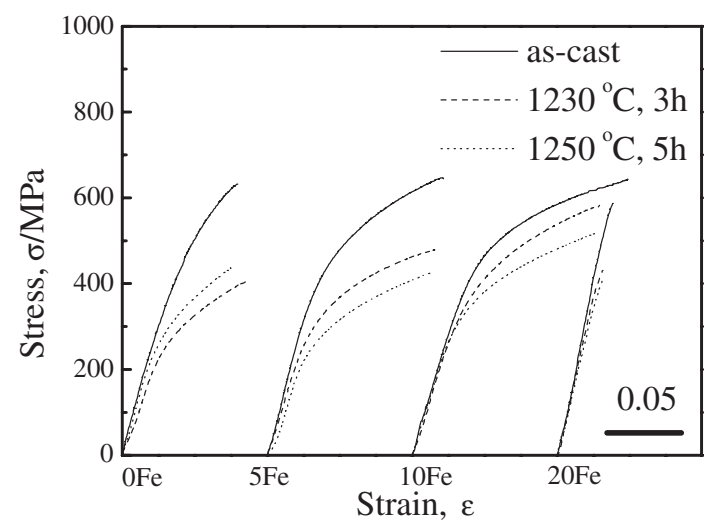

Fig. 6 Effect of Fe addition and heat treatment condition on the stressstrain curve of Co-29Cr-6Mo alloys.

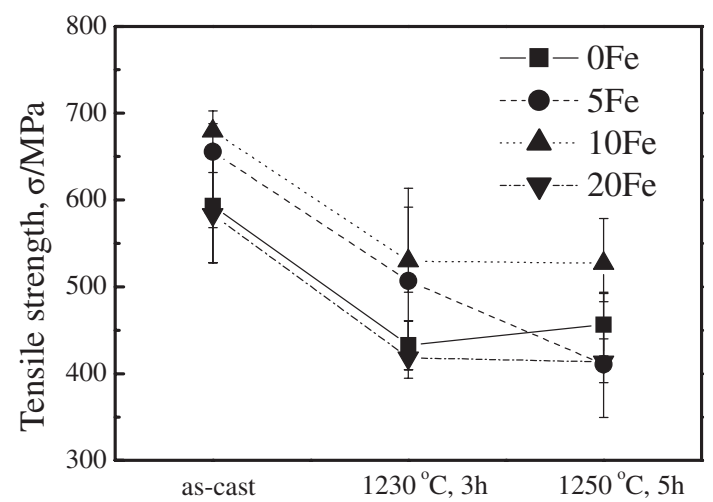

Fig. 7 Effect of Fe addition and heat treatment condition on the tensile strength of Co-29Cr-6Mo alloys.

phase of 5Fe completely disappeared, and small amount of $\sigma$ phase observed in $10 \mathrm{Fe}$ by heat treatment. From the results of microstructural observations, the $\bar{N}_{v}$ value between 2.80 and 2.85 is more appropriate in this study. Thus the optimum content of $\mathrm{Fe}$ that does not precipitate the $\sigma$ phase in Co$29 \mathrm{Cr}-6 \mathrm{Mo}-x \mathrm{Fe}$ is believed to lie between 5 and 10 mass $\%$.

\subsection{Mechanical properties}

Figure 6 shows the representative stress-strain curves of Fe-added Co-29Cr-6Mo alloys. The ductility increases with Fe content up to 10 mass $\%$, whereas it suddenly decreases at Fe content of 20 mass $\%$. For $10 \mathrm{Fe}$ alloy, the ductility of the heat-treated alloys has a similar behavior to that of the as-cast alloy and shows good match with tensile strength. The stressstrain curves of $20 \mathrm{Fe}$ show linear behavior, meaning lack of ductility. This is due to a higher content of $\sigma$ phase as mentioned in the previous section. Unlike $\mathrm{Ni}$ addition, increasing the amount of $\mathrm{Fe}$ content forms increased the volume not only of $\gamma$ phase but also of $\sigma$ phase in Co-Cr-Mo alloys. Thus it is found that the amount of $\mathrm{Fe}$ addition to Co29Cr-6Mo alloys should be limited to a value lower than 10 mass \% to avoid the poor ductility and tensile strength. The tensile strength and elongation of experimental alloys are shown in Figs. 7 and 8, respectively. The tensile strength and the elongation increases with increasing $\mathrm{Fe}$ content and decreases with increasing heat treatment temperature except

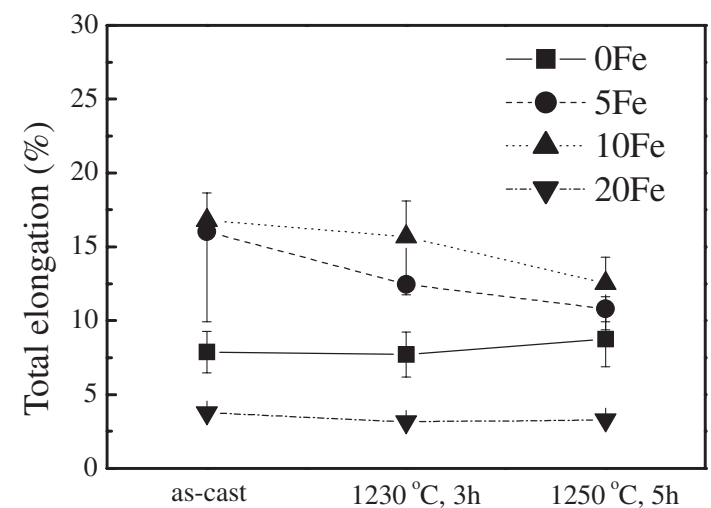

Fig. 8 Effect of Fe addition and heat treatment condition on the elongation of Co-29Cr-6Mo alloys.

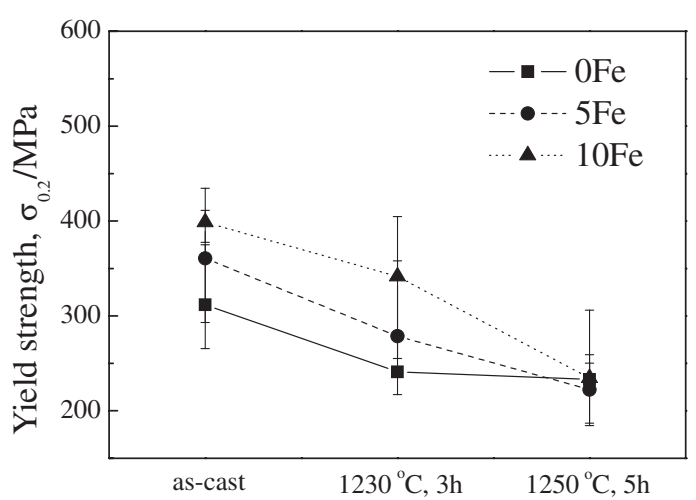

Fig. 9 Effect of Fe addition and heat treatment condition on the yield strength of Co-29Cr-6Mo alloys.

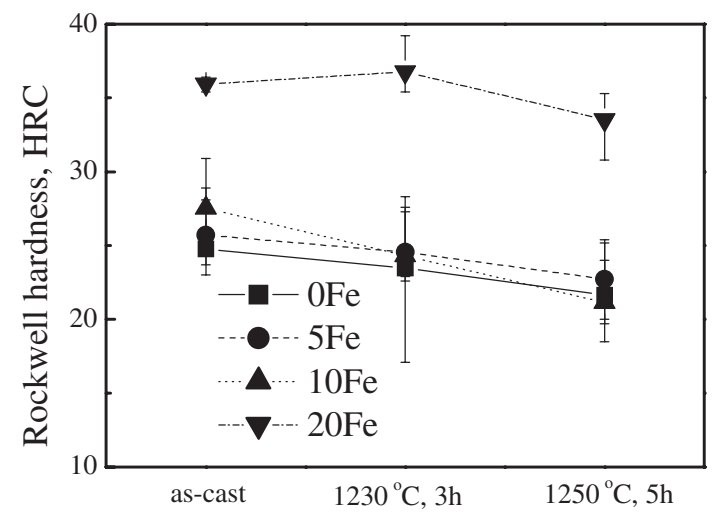

Fig. 10 Effect of Fe addition and heat treatment condition on the Rockwell hardness of Co-29Cr-6Mo alloys.

for $20 \mathrm{Fe}$. This is due to grain growth which occurs with heat treatment. After heat treatment at $1250^{\circ} \mathrm{C}$ for $5 \mathrm{~h}$, the yield strength of experimental alloys is almost the same irrespective of Fe content (Fig. 9). This suggests that the strengthening effect caused by $\mathrm{Fe}$ addition is alleviated due to grain growth during the heat treatment. The change of hardness with Fe content and with heat treatment is shown in Fig. 10. The hardness slightly increases with $\mathrm{Fe}$ addition up to 10 mass $\%$. On the other hand, the hardness values of $20 \mathrm{Fe}$ 
alloys greatly increase because of a large amount of precipitation of the $\sigma$ phase. Heat-treated alloys show reduced hardness compared to the as-cast alloys, resulting from the grain growth.

The present study reveals that as-cast specimens are superior to heat-treated specimens in the aspect of mechanical properties. However, since the heat treatment is inevitable to obtain segregation-free microstructure, the mechanical properties of the heat-treated alloys are important for optimization of the hot forging condition. Thus it is concluded that the optimum Fe content lies between 5 and 10\%, and that the optimum heat treatment temperature and time are higher than $1230^{\circ} \mathrm{C}$ and longer than $3 \mathrm{~h}$, respectively.

\section{Conclusion}

The alloying effect of $\mathrm{Fe}$ on the microstructures and mechanical properties of $\mathrm{Ni}$ - and $\mathrm{C}$-free $\mathrm{Co}-\mathrm{Cr}-\mathrm{Mo}$ alloys was investigated, and the following results were obtained.

(1) The retained volume fraction of $\gamma$ phase at room temperature increases with increasing Fe content and heat treatment temperature and time.

(2) The amount of $\sigma$ phase increases with increasing $\mathrm{Fe}$ content.

(3) The yield stress, the tensile strength, the hardness, and the elongation increase with increasing $\mathrm{Fe}$ content, whereas they decrease with increasing heat treatment temperatures and time due to grain growth.

(4) The amount of Fe should be limited to a concentration lower than 10 mass $\%$ for having a good match between microstructures and mechanical properties.

\section{Acknowledgement}

This research was supported by a Cooperation of Innovative Technology and Advanced Research in Evolutional Area from the Ministry of Education, Science and Culture of Japan.

\section{REFERENCES}

1) A. J. T. Clemow and B. L. Daniell: J. Biomed. Mater. Res. 13 (1979) 265-279.

2) R. W.-W. Hsu, C.-C. Yang, C.-A. Huang and Y.-S. Chen: Mater. Chem. Phys. 93 (2005) 531-538.

3) H.-C. Hsu and S.-S. Lian: J. Mater. Pro. Tech. 138 (2003) 231-235.

4) T. Kilner, W. M. Laanemae, R. Pilliar, G. C. Weatherly and S. R. MacEwen: J. Mater. Sci. 21 (1986) 1349-1356.

5) L. Z. Zhuang and E. W. Langer: J. Mater. Sci. 24 (1989) 381-388.

6) A. de J. Saldivar Garcia, A. Mani Medrano and A. Salinas Rodriguez: Scr. Mater. 40 (1999) 717-722.

7) LongQuan Shi, D. O. Northwood and ZhengWang Cao: J. Mater. Sci. 28 (1993) 1312-1316.

8) D. L. Klarstrom: J. Mater. Eng. Per. 2 (1993) 523-530.

9) Sang-Hak Lee, Eiji Takahashi, Naoyuki Nomura and Akihiko Chiba: Mater. Trans. 47 (2006) 287-290.

10) J.-C. Shin, J.-M. Doh, J.-K. Yoon, D.-Y. Lee and J.-S. Kim: Surf. Coat. Tech. 166 (2003) 117-126.

11) T. Ericsson: Acta Metall. 14 (1966) 853-865.

12) S.-H. Lee, E. Takahashi, N. Nomura and A. Chiba: Mater. Trans. 46 (2005) 1790-1793.

13) S.-H. Lee, T. Uchikanezaki, N. Nomura, M. Nakamura and A. Chiba: Mater. Trans. 48 (2007) 1084-1088.

14) H. J. Murphy, C. T. Sims and A. M. Beltran: the 1st Inter. Symposium on Structural Stability in Superalloys, (Champion, Pennsylvania, 1968) pp. $47-66$.

15) L. R. Woodyatt, C. T. Sims and H. J. Beattie: Trans. AIME 236 (1966) 519-527. 